\title{
O auto-retrato na fotografia contemporânea. Que resta do sujeito, tecnicamente falado?
}

\author{
Pot Eduarda Neves*
}

Self-portrait in contemporary photography. What is left of the subject, technically speaking?

\begin{abstract}
$O$ auto-retrato na fotografia contemporânea. Da ilusão da semelhança da realidade à ilusão da representação da identidade. O paradoxo como categoria tensional do auto-retrato.

PALAVRAS CHAVE: Fotografia, Arte contemporânea, Autoretrato, Identidade, Paradoxo

ABSTRACT

Self-portrait in contemporary photography: from the illusion of realities's resemblance to the illusion of identities's representation. Paradox as self-portrait's tensional category.

KEYWORDS:

Photography, Contemporary art, Selfportrait, Identity, Paradox

O cosmos também pode ser procurado dentro de cada um de nós, como caos indiferenciado, como multiplicidade potencial'.
\end{abstract}

Assistimos a partir das últimas décadas do século XX à exploração da virtualidade do medium fotográfico e ao questionamento da fotografia como prática isolada num certo purismo modernista. A abertura que, sobretudo a partir dos anos setenta, os artistas, as instituições do mundo da arte, como galerias ou museus, revistas e outros espaços discursivos da arte manifestam em relação à fotografia, contribuem para a sua legitimação como paradigma das artes visuais, revelando o carácter desde sempre eclético deste meio.

\footnotetext{
* eduardadn@gmail.com

Assistente na Escola Superior Artística do Porto (Porto/ Portugal)

1 CALVINO, I.- «Começar e Acabar». Seis Propostas para o próximo milénio. Lisboa: Editorial Teorema, p. 155.

Este artigo enquadra — se no processo de investigaçao que nos encontramos a desenvolver no âmbito da Tesé de Dontoramento dirigida pelo Professor Simón Marelrán Fez, no Departamento de Filosofia Social e Política da UNED.
} 
A imagem fotográfica contribuirá para o esbatimento de fronteiras entre práticas artísticas afirmando-se como plataforma crítica para um conjunto de questões que atravessarão o campo da arte: Porque ocupa uma posição media entre arte/não arte, entre os domínios artísticos diversos, a fotografia pôde nas últimas décadas questionar a especificidade da arte e dos seus usos tradicionais. Pôs em relação as práticas e conceitos até aí vistos como operacionais em campos separados. As obras que inauguram esta transformação foram realizadas entre 1965/70 pelos artistas do comportamento, da performance e do conceptual. (...) No final dos anos 60, vários artistas estão fartos da fotografia dita artística e inauguram uma escrita fotográfica da arte conjugando dois conceitos: " $A$ fotografia como arte» de Sontag e «a arte enquanto fotografia» de Benjamim. Fotografia e arte tornam-se objecto de reflexão teórica que se desenvolve ao longo dos anos 80 na Europa e nos Estados Unidos².

A partir da imagem fotográfica serão reequacionadas noções como as de arte e não-arte, espaços de legitimação, alta e baixa cultura ${ }^{3}$, imagem e representação, aura, múltiplo, original e apropriação, arquivo, documento e história, memória e tempo, real e ficção, objectividade e subjectividade, género, estilo e autor, identidade e sujeito, feminino e masculino, corpo e sexualidade, ideologia, poder e política ou ainda o retrato e o auto-retrato: Ao conceito de um sujeito auto-reflexivo e livre a priori que, das Meditações de Descartes ao existencialismo sartriano, se comprometia numa reflexão teórica e moral continua, opôs-se uma interrogação crítica e ideológica sobre o que, do exterior, constitui o sujeito, sobre o que o «trama», apesar dele, fora delet.

Como que paradoxalmente, e contrariando os conhecidos obstáculos à legitimação da fotografia como arte desde o seu aparecimento, caberá assim à imagem fotográfica afirmar-se como espaço de reflexão das grandes questões que atravessam o campo da arte na última metade do século $\mathrm{XX}$, entre as quais sobressai

2 COUDERC, S. - «Photographie et art contemporain». La recherche photographique. Europe 1970-1990, no 13, Paris, Automne 1992, p. 12

${ }^{3} \mathrm{Se}$ «qualquer pessoa é artista» e este artista é um fotógrafo, converter-se-á nisso no momento em que o equipamento fotográfico de alta resolução se liberta da posse de culto de que gozavam os especialistas e passa a um estado de disponibilidade para toda a gente, no auge do consumismo. Os mundos de Beuys e McLuhan entrelaçam-se, embora o cidadão médio consiga fazer-se com um equipamento «profissional». A «grande» arte fundou a ideia(ou o ideal) da competência ilimitada, o maravilhoso do talento em continua evolução.(...) Para o artista com talento e habilidade, imitar uma pessoa de capacidades limitadas converteu-se num acto criativo e subversivo. Era uma experiência nova, que ia contra todas as ideias aceites sobre arte e era um dos últimos gestos que podia provocar um impacto vanguardista.(...) Esta mimesis significava, ou exprimia, o desaparecimento das grandes tradições da arte occidental e a sua conversão nas novas estruturas culturais estabelecidas pelos meios de comunicação, os créditos de financiamento, as urbanizações das zonas residenciais e a burocracia reflexiva.WALL, J.—» «Senales de indiferencia»: aspectos de la fotografia en el arte conceptual o como arte conceptual» - Indiferencia y singularidad. (Glòria Picazo/Jorge Ribalta eds.). Barcelona:Editorial Gustavo Gili, 2003, pp. 244-245.

${ }_{4}^{4}$ BAQUÉ, D. - Photographie Plasticienne, LÉxtrême Contemporain.Paris: Éditions du Regard, 2004, p. 201 
O auto-retrato na fotografia contemporânea. Que resta do sujeito, tecnicamente falado?

a noção de Aura que, desde Walter Benjamin, vem sendo requacionada, sobretudo no quadro do uso da fotografia nas práticas artísticas das últimas décadas ${ }^{5}$.

No seu texto A Obra de arte na época da sua possibilidade de reprodução técnica, Walter Benjamin aponta os factores específicos que, do seu ponto de vista, condicionam o declíneo da aura. Esta não aparece associada a um ideal romântico que suscita a nostalgia e à luz da qual, entre outros aspectos, Benjamin justificava a perda do culto das obras de arte. Situando-se fundamentalmente no domínio espiritual, sentimental e até teológico, a aura objectiva-se, segundo o autor, na harmonia e beleza das obras de arte e está impregnada das marcas da tradição.

Sendo premonitória de marcas da sociedade e cultura contemporâneas, a abordagem de Benjamin, como observou Susan Sontag é, hoje, questionável. Como esta autora acentuou (...) também se pode dizer que uma fotografia de Atget, impressa no papel que ele utilizava e que hoje é impossível de obter, tem uma aura $^{6}$. E vai mais longe a autora: não e' em Muita pintura actual aspira às características de objectos reprodutíveis. (...) Temos hoje obras de arte produzidas com o objectivo de serem fotografadas. (...) Agora toda a arte aspira a ser fotografia ${ }^{7}$.

Da fotografia como arte à arte como fotografia de Sontag e, como que concretizando a profecia de Benjamin, será de facto a imagem fotográfica a contribuir para a transformação da noção tradicional de Arte a que assistimos à quase meio século ${ }^{8}$.

Sabemos que a ampliação dos limites da arte e dos seus consumidores serviu os interesses do poder económico, aumentando não só a oferta mas também a procura $^{9}$, tornando qualquer objecto possível de se tornar musealizável e adquirir «aura», o que mostra que o sistema da arte não entrou em colapso mas que se reorganizou e fortaleceu.

\footnotetext{
5 Nos anos imediatamente seguintes à edição da Documenta 5, organizaram-se imensas mostras seja na Europa seja nos Estados Unidos, para explorar o ponto de encontro entre arte e fotografia. $\mathrm{Na}$ Alemanha houve logo a mostra de um grupo como o "Medium Fotografie» (Stadtisches Museum Leverkusen,1973;» Arte da Fotografia «(Kunstverein Hannover, 1973;» Foptomedia «(Museum am Oswall, Dortmund, 1973); «Fotografia Demonstrativa «(Heidelberg Kunstverein, 1974); «Fotografia como Arte/Arte como Fotografia» (Fotoforum Kassel, 1975); «Memórias fotografadas «(Kunstverein Hannover, 1976); e «Foto-sequências de Artistas contemporâneos"(Kunstverein Hamburg, 1977. Estas mostras, entre outras, fazem parte de uma crescente actividade que compreenderá todo um conjunto de escritos críticos e teóricos sobre a relação entre a arte e a fotografia, uma completa reconstrução da história da fotografia e de uma fervente aproximação a obras de fotografia dap arte de museus e do mercado da arte. Christopher Phillips - «L' IMMAGINE FANTASMA: La Fotografia nell'arte europea e Americana del dopoguerra.» In L'IMMAGINE RIFLESSA. Museo Pecci, Marzo, 1995, p. 20.

6 SONTAG, S.- Ensaios sobre fotografia. Lisboa, Publicações Dom Quixote, 1986, pp. 126-127.

7 SONTAG,S. - Op. Cit., pp. 133-134

8 Como salientou Rosalind Krauss, Duchamp foi o que provocou a mudança mais radical, a passagem do tradicional conceito de ícone ao de índice." Marcel Duchamp ou o campo imaginário» pp. 76-94. KRAUSS, R. - O Fotográfico. Barcelona:, Editorial Gustavo Gili, SA, 2002.

${ }^{9}$ E' evidente a presença cada vez maior da fotografia nos múseus o que nos conduz a repensar a História da Arte tradicional e as instáncias de legitimaçao como o museu.
} 
A propósito da entrada da fotografia no museu e nas bibliotecas, Douglas Crimp entende-a, por um lado, como uma ferramenta perversa da modernidade mas, por outro, como um facto positivo, na medida em que define a radicalização de uma prática artística nova e que deve ser designada como pós-moderna. A fotografia constitui (tal como posteriormente o video) nas últimas décadas do século $\mathrm{XX}$, o meio a partir do qual a arte se pensará a si mesma: a fotografia penetra na prática artística de tal maneira que contamina a pureza das categorias separadas da modernidade, as categorias da pintura e escultura: Por trás de um século de enclausuramento da arte dentro do discurso da modernidade e da instituição do museu, hermeticamente selado para o resto da cultura e da sociedade, a arte da pós-modernidade começa a incidir de novo no mundo. Em parte é a fotografia que o torna possível, embora tenha que fazer frente ao atavismo do realismo tradicionallo.

Conta ainda Douglas Crimp que há alguns anos uma bibliotecária que trabalhava na secção de arte e arquitectura da New York Public Library começou a interessar-se pela fotografia e, quando começa a aprofundar o estudo descobriu que a biblioteca tinha, entre outros exemplos, dispersas em várias das suas secções, uma série de livros com originais fotográficos antigos, particularmente do século XIX, bem como ilustrações fotográficas, imagens de arqueologia. Decidiu então fazer uma exposição com todo esse material e enquanto a organizava os preços das fotografias aumentaram no mercado o que levou a que alguns dos originais valessem muito dinheiro, quando há anos atrás nem na secção de livros raros da biblioteca valia a pena colocá-los.

A imagem fotográfica, adquirindo o carácter fetichista da obra de arte, ganha valor de troca e torna-se objecto estético. Sem perder a sua qualidade de multiplicação e continuando a servir para a reprodução, a «aura» permitirá a entrada da fotografia nos museus e a sua inserção nas secções de arte das livrarias subtraindo-a a um mero carácter utilitário, informativo, ilustrativo ou documental. Quando entram no museu nunca mais serão as mesmas e talvez o museu também não seja mais o mesmo.

O museu mergulhará inevitavelmente na ausência de paradigma legitimador ou de uma instância a partir da qual as obras se validem como arte. Aporia ou perversão? Ou, como defende Boris Groys, (...) se falamos sobre arte é importante recordar que ninguém na actualidade sabe o que é ou não é arte. É uma questão de perspectiva. Em qualquer caso, a arte estaria definida de uma forma muito limitada se a considerassemos unicamente sob as condições em que é produzida e distribuida pelas galerias ${ }^{11}$.

10 CRIMP, D. et allii — «Del museo a la biblioteca»- Indiferencia y singularidad (Glòria Picazo/Jorge Ribalta eds.). Barcelona: Editorial Gustavo Gili, 2003, p. 47.

11 Entrevista com Boris Groys - EXIT Express, \# 33 - Febrero, 2008,p. 83. 
O auto-retrato na fotografia contemporânea. Que resta do sujeito, tecnicamente falado?

No entanto, também não podemos ignorar que a fotografia assegurará aos artistas todo um programa conceptual do qual uma boa parte dos fotógrafos estava afastado, na medida em que o programa destes era, fundamentalmente, um programa técnico travestido de um sentimentalismo ora humanista e metafísico, ora expressivo. Os fotógrafos de tradição modernista - a grande maioria- continuavam alheados das questões da arte contemporânea: (...) esta fotografia dos artistas não tinha pontos comuns com a fotografia dos fotógrafos que continuava polarizada na questão da representação: seja esforçando-se em reproduzir literalmente as aparências (como a fotografia-documento); seja afastando-se delas (como a fotografia-expressão); seja transformando-as deliberadamente (como a fotografia artística). A fotografia dos artistas (...) não pertence ao domínio da fotografia, mas ao da arte. É que a arte dos artistas é também distinta da arte dos fotógrafos tal como a fotografia dos artistas o é da dos fotógrafos ${ }^{12}$.

No âmbito das múltiplas tendências da arte contemporânea, o uso experimental e crescente da fotografia ${ }^{13}$ materializa-se, talvez ainda por influência de uma das secções mais significativas da Documenta 5, a secção Mitologias Individuais, em práticas artísticas que experienciam a explosão do sujeito(s) e da(s) subjectividade(s): auto-retrato, auto-representação, memórias individuais e colectivas, esfera da vida pessoal e familiar, privacidades e intimidades, sexualidade e transgressão, entre outras narrativas do sujeito.

A experiência da subjectividade e a construção de si, a fragmentação, a transparência ou a morte do sujeito, não foram moda apenas na filosofia: $o$ sujeito foi $o$ índice de todas as errâncias da filosofia. Base do idealismo, ilusão do existencialismo, pálido reflexo de um humanismo em desuso, será associada aos esforços desesperados de uma filosofia que já não tinha objecto. (...) Não nos libertamos tão facilmente de uma problemática do homem ${ }^{14}$.

12 ROUILLÉ. A. - La photographie. Paris: Éditions Gallimard, 2005, p. 382.

13 (....) a «desmaterialização da obra» perseguida pel arte conceptual nunca se pôde cumprir sem o apoio da fotografia, do meio técnico capaz de deixar memória e registo do seu acontecimento social, da sua recepção pública. A posterior identificação da obra -performance, intervenção, construção dramatúrgica, etc. - com essa sua reprodução técnica, fundamenta todo o desenvolvimento da arte pósconceptual e não é por acaso que todo o conceptualismo contemporâneo é precisamente el foto-conceptualismo.

É esta, então, a linha interpretativa com a qual devemos aproximar-nos à contemporânea proliferação dos usos da fotografia por parte dos artistas, não aceitando nenhum desprezo pelo potencial crítico que existe no actuar problematizador dos processos de distribuição e recepção social do conhecimento artístico, que é próprio da arte de vanguarda e em relação à qual a natureza técnica do meio fotográfico ostenta uma qualidade específica e irredutível. BREA. J.L. — «El inconsciente óptico y el segundo obturador. La fotografia en la era de su computerización». Papel Alpha. Cuadernos de fotografia. $n^{\circ}$ 1, 1996, p. 18. Mais adiante assinala o autor que (...) esta virtualidade artística da fotografia - que se funda no seu potencial antiartístico, desconstrutivo precisamente - é predominantemente utilizada com carácter «instrumental» pelos «artistas», embora no seu uso pelos «fotógrafos puros», digamos, as pretensões de artisticidade vinculam-se sobretudo à exploração das potencialidades «simbólicas" da fotografia como quadro, na organização picotrica da sua superfície - esbatida todavía por la fantasia paranóica da pintura, da imitação, p. 22.

14 VEDRINE, H. — Le sujet éclaté. Paris:Librairie Générale Française, pp. 12-12. 
A morte do sujeito triunfará igualmente na arte. Os artistas ultrapassarão o paradigma que tendia a conceber o auto-retrato como «essência «do artista, referência idealizadora da identidade do modelo ou espaço de encontro introspectivo e de descoberta de um si mesmo. A mutabilidade, a decomposição e o envelhecimento, o vazio, a fragilidade e ruína dos corpos e a efemeridade ou ficção das identidades, o eu e o outro, não escapam à problemática do homem ${ }^{15}$; restauram figuras do sujeito ou, pelo menos, de certas representações do sujeito, mesmo que da sua morte se trate; o sujeito da enunciação integra o próprio enunciado.

O sujeito encena-se a si mesmo, propõe-se tanto como lugar de auto-reconhecimento ou lugar da alteridade: (...) com efeito, outrem não é um outro Eu, mas o Eu é um outro, um Eu rachado. Não há amor que não comece pela revelação de um mundo possível como tal, enrolado em outrem que o exprime ${ }^{16}$.

Ferramenta auto-referencial, o auto-retrato expõe as contradições, complexidades, paradoxos ou limites do sujeito.

Se com a modernidade o indivíduo se institui como modelo e referência, as experiências pessoais e as idiossincrasias individuais adquirem uma existência soberana e, se a subjectividade foi abordada por grandes modelos de interpretação, como o marxismo ou a psicanálise, os finais do século XX são acompanhados por múltiplas interrogações sobre os limites do sujeito, a sua presença singular no mundo. O privado e o íntimo suscitam um interesse quase que obsessivo, a identidade é potencializada não como algo único e constante mas como um eu constituído por tantos «nós» tantos» eus», auto-representações que tecem o auto-retrato.

15 Respondeu Michel Foucault quando Ihe pediram para definir o lugar e significado do humanismo na cultura ocidental: Cremos que o humanismo é uma noção muito antiga que remonta a Montaigne e até mais além. Ora, a palavra «humanismo" não existe nos Ensaios. Na verdade, com essa tentação da ilusão retospectiva à qual sucumbimos muito frequentemente, imaginamos de boa vontade que o humanismo sempre foi a grande constante da cultura ocidental.(...)No ensino secundário, aprendemos que o século XVI foi a era do humanismo, que o classicismo desenvolveu os grandes temas da natureza humana, que o século XVIII criou as ciências positivas e que chegamos enfim a conhecer o homem de maneira positiva, científica e racional com a biologia, a psicologia e a sociologia.(...) O que nos admira na nossa cultura actual, é que ela possa ter a preocupação com o humano. Esse falamos de barbárie contemporânea, é na medida em que as máquinas, ou certas instituições, nos aparecem como não humanas.Tudo isso é da ordem da ilusão. Primeiramente, o movimento humanista data do fim do século XIX. Em segundo lugar, quando se olha ligeiramente as culturas dos séculos XVI, XVII e XVIII, percebe-se que o homem não tem literalmente nenhum lugar. A cultura é então ocupada por Deus, pelo mundo, pela semelhança das coisas, pelas leis do espaço, e certamente também pelo corpo, pelas paixões, pela imaginação. Mas o homem mesmo é completamente ausente. E As Palavras e as Coisas, quis mostrar de quais peças e de quais pedaços o homem foi composto no fim do século XVIII e início do XIX. Tentei caracterizar a modernidade dessa figura, e o que me pareceu importante era mostrar isso: não é tanto porque se teve um cuidado moral com o ser humano que se teve a ideia de conhecê-lo cientificamente, mas é pelo contrario porque se construiu o ser humano como objecto de um saber possível que em seguida se desenvolveram todos os temas morais do humanismo contemporâneo, temas que são encontrados nos marxismos frouxos, em Saint-Exupéry e Camus, em Teilhard de Chardin, em todas essas figures pálidas da nossa cultura. FOUCAULT, M.- Dits et Écrits. Paris: Gallimard, 1994, vol. I, pp. 540-541.

16 DELEUZE, G. — Diferença e Repetição. São Paulo: Edições GRAAL,1988, p. 414. 
O auto-retrato na fotografia contemporânea. Que resta do sujeito, tecnicamente falado?

Reflectindo sobre a relação entre Sócrates e Alcibíades, Michel Foucault salienta que no texto Alcibíades, de Platão, o ocupar-se de si mesmo divide-se em duas perguntas: (...) quem é este si mesmo que há que cuidar e em que consiste este cuidado? Em primeiro lugar, o que é o si? O si é um pronome reflexivo e tem dois sentidos. Auto significa «o mesmo», mas também implica a noção de identidade. O sentido mais tardio desloca a questão para "Quem é este si mesmo?» até «Qual é o marco no qual poderei encontrar a minha identidade?»17

Desde o início do século XIX que o conceito de identidade se torna um aspecto central da discursividade moderna. Significando etimologicamente a mesma entidade, nele se potencializou uma rede de significações políticas, culturais, estéticas, ideológicas e económicas.

Enquanto forma discursiva e artística própria o auto-retrato contemporâneo constitui o espaço de um Eu expandido, que encontra voz na fuga aos discursos de pressupostos ontologizantes, humanistas ${ }^{18}$ e essencialistas, um sujeito que se constrói em processo, o qual vai integrando a sua própria identidade sem ceder à tentação do pensamento e da cultura dialéctica ${ }^{19}$.

A escrita de $\mathrm{si}^{20}$, enquanto formulação auto-referencial, reinventa e transforma o sujeito durante o processo de subjectivação. Aquele que cria a obra é igualmente por ela e nela criado. Esta auto-referencialidade permite-nos apreender o Eu como espaço de auto-ficcão: (...) uma ficção é uma representação em que a coisa representada é considerada inexistente. Ou seja, a ficção é uma representação descomprometida ontologicamente. Por outras palavras, a ficção será uma representação a que o sujeito não atribui existência real. (...) O mesmo é dizer que a

17 FOUCAULT, M. -Tecnologías del yo. Barcelona: Ediciones Paidós Ibérica, S.A., 1990, p. 58.

${ }_{18} \mathrm{O}$ que ignora o homem, é a razão analítica contemporânea que se viu nascer com Russell, e que aparece em Lévi-Strauss e nos linguístas. Esta razão humanista é incompatível com o humanismo, enquanto que a própria dialéctica se nomeia acessoriamente de humanismo.

Ele nomeia-se por várias razões: portque é uma filosofia da alienaçãone da reconciliação. Por todas essas razões e porque continua, no fundo, uma filosofia de retorno a si mesmo, a dialéctica promete em certa medida ao ser humano que ele se tornará um homem autêntico e verdadeiro. Ela promete o homem ao homem e, nessa medida, não é dissociável de uma moral humanista. Neste sentido, os grandes responsáveis do humanismo contemporâneo, são evidentemente Hegel e Marx. (...) Esta cultura não dialéctica que está a caminho de se formar é ainda muito balbuciante por diversas razões. Primeiro, porque tem aparecido espontaneamente em regiões extremamente diferentes. Ela não tem lugar privilegiado.(...) Ela começou com Nietzsche quando mostrou que a morte de Deus não era o aparecimento, mas o desaparecimento do homem, que o homem e Deus tinham estranhos parentescos(....) Ela apareceu igualmente em Heidegger, quando tentou retomar a abordagem fundamental do ser num retorno à origem graga. Apareceu igualmente em Russell quando fez a crítica lógica da filosofia, em Wittgenstein quando colocou o problema das relações entre lógica e linguagem, nos linguístas e nos sociólogos com Lévi-Strauss. FOUCAULT, M. - Dits et Écrits. Paris:Gallimard,1994, vol. I, pp. 541-542.

19 Parece-me que o pensamento não dialéctico que se constitui agora não põe em jogo a natureza ou a existência, mas isso que é o saber.(...) Ele terá que se interrogar sobre a relação que pode haver, por um lado, entre os diferentes domínios do saber e, por outro lado, entre saber e não-saber.(...) um não suprime o outro; estão em relação constante, apoiam-se um no outro e podem ser compreendidos apenas um através do outro. FOUCAULT, M., Op. Cit., pp. 542-543.

20 Encontramos o terreno do auto-retrato, do ensaio, da meditação,do diário e de outras formas de escrita de si na autobiografia clássica 
ficção tem um alcance maior do que o da verosimelhança. Acontece mesmo que se pode tornar verosímil a ficção que hoje é inexistente e impossível (...). Na sua função estética o sujeito introduz provisoriamente o descomprometimento ontológico, isto é, o facto de pensar como inexistente a coisa representada. O jogo de linguagem é introduzido pela proposição como se ${ }^{21}$.

Trata-se da verdade construída e da identidade fabulada, sobre a qual se pode, simultaneamente, contar várias narrativas; não se trata da mesma história com pontos de vista diferentes mas de histórias efectivas, diversas e divergentes. Para Raymond Bellour (...) O auto-retrato reveste-se a partir do século XIX de todos os avatares da crise da representação ${ }^{22}$. Posicionando-se entre o documento e a ficção ${ }^{23}$, o auto-retrato faz explodir as tentações redutoras das formas totalizantes. A sua aproximação é à indeterminação e à imprevisibilidade. O paradoxo como categoria tensional do auto-retrato.

A experiência da despersonalização é a aventura de Alice, a de saber que um nome pode ter todos os sentidos. Através do paradoxo se destrói, segundo Deleuze, o sentido único que caracteriza o bom senso e o senso comum como aquilo que define as identidades fixas ${ }^{24}$.

A problematização que nas últimas décadas encontramos no campo da arte, em torno da fronteira entre documental e ficção, verdade e objectividade, identidade e alteridade (que o recurso à imagem fotográfica na construção do auto-retrato tão claramente explora) comporta a ideia de que esse retrato de si faz ressoar territórios de alteridade. Não tanto implicação mas complicação, diz Deleuze.

A paixão pelo real retorna pela imagem fotográfica, não como promessa de verdade mas, antes, para desmaterializar e reinventar as ilusões da identidade.

A dissolução dos limites da arte parece acompanhar a dissolução dos limites do sujeito, de um eu entendido como identidade segura. Como argumenta Peter Sloterdijk as filosofias tradicionais já não são suficientes para tentar responder ao

${ }^{21}$ MARQUES. A. - «Ficção e representação: Nota sobre o conceito de representação e as suas conexões estéticas.» Revista de comunicação e Linguagens. Ficções. Dezembro de 2003, no 32, pp. 15-16.

22 BELLOUR, R. - Entre- images. Paris: Ed.1997, p. 288.

23 (...) o artista actual não elabora representações orgânicas "da realidade», mas, antes, activa a desconstrução sistemática de tais representações. De facto, não se pode atribuir a um jogo de linguagem a intenção de alguma «representação»: no se trata de «representar» uma suposta realidade, mas pôr em cena segmentos enunciativos que colocam dúvidas sobre a ordem da representação estabelecida. $\mathrm{A}$ importância que nas linguagens visuais dos anos 90 cobra esta familia de procedimentos enunciativos constitui, sem dúvida, um dos seus mais inconfundíveis traços.BREA. J.L. - Op. Cit. p. 21.

${ }^{24} \mathrm{O}$ bom senso é a afirmação de que, em todas as coisas, há um sentido determinável; mas o paradoxo é a afirmação dos dois sentidos ao mesmo tempo. DELEUZE, G. - Lógica do Sentido.São Paulo: Editora Perspectiva, 1998, p. 1. E mais à frente diz Deleuze: O paradoxo deste puro devir, com a sua capacidade de furtar-se ao presente, é a identidade infinita: identidade infinita dos dois sentidos ao mesmo tempo, do futuro e do passado, da véspera e do amanhã, do mais e do menos, do demasiado e do insuficiente, do activo e do passivo, da causa e do efeito.(...) A perda do nome próprio é a aventura que se repete através de todas as aventuras de Alice. Pois o nome próprio ou singular é garantido pela permanência de um saber, pp. 2-3. 
O auto-retrato na fotografia contemporânea. Que resta do sujeito, tecnicamente falado?

que é o sujeito e ao que é a subjectividade: O facto de a filosofia moderna ter colocado o seu princípio na subjectividade activa já indica, por certo, que ela encontrou coragem para se lançar numa aventura que faz história, a fim de poder esperar o máximo da sua própria actuação no mundo. Que é a filosofia da subjectividade senão uma maquinaria lógica que julga ter identificado no sujeito que pensa e age livremente o cumpridor de todas as promessas possíveis? ${ }^{25}$

Não deixa de ser ilustrativo que a prática do auto-retrato, tal como se configura nas últimas décadas do século $\mathrm{XX}$, abandone a ideia de que o conhecer-se a si próprio seja sinónimo da definição de uma qualquer identidade ou o assentimento de uma imagem de si até agora em segredo mas, sobretudo, o confronto com uma espécie de estranhamento: (...) Que resta, pois, do pathos da razão que nos deveria ter dito o que somos? O imperativo da sapiência, "Conhece-te a ti próprio!», transforma-se na divisa existencial: "Sê tu próprio!» É uma divisa ontológica de cavalheiro, que deixa a todos os parentes da casa a liberdade de ser aquilo que quiserem, contanto que simplesmente se lembrem de ser aquilo que quiserem, contanto que se lembrem de que existir significa ser da melhor família. (...) Mas, abstraindo do efeito exaltante, a máxima "Sê tu próprio!" é um tanto pálida de mais para orientações práticas nessa região. (...) Por isso "Sê tu próprio!» quer também dizer. «Inventai-vos!»26 Pensar a identidade como diferença, como disparidade de fundo ${ }^{27}$.

Com a consolidação do reconhecimento da imagem fotográfica como suporte dotado de potencialidades críticas, bem como a necessidade de reflectir sobre a ligação da arte contemporânea às tecnologias, a fotografia afirma-se como ferramenta do operar artístico, permitindo que as tecnologias se afastem, como refere Gloria Picazo, (...) das disciplinas artísticas tradicionais, pois a sua inclinação para a fotografia não se devia tanto a que a valorizassem como uma das belas artes, mas pela sua imediatez, a sua facilidade de manipulação, o seu carácter popular, tão afastado do "cultismo» artístico que combatiam. Além disso permitia-Ihes um deslocamento do objecto de desejo para o sujeito de desejo, questionando-se consequentemente o valor da obra de arte como tal e, até mesmo, a sua própria existência e relação com o contexto sócio-político. Ao mesmo tempo, a fotografia abria-Ihes novas possibilidades de reflexão face aos temas recorrentes da história

25 SLOTERDIJK,P. - A Mobilização Infinita. Para uma crítica da Cinética Política. Lisboa: Relógio d’Água, Editores, 2002, p. 127. E continua o autor mais adiante: Por ser ele póprio a cumprir as promessas que Ihe foram feitas, o sujeito pára a sua queda numa fase suportável. Essa paragem é o esforço-que-eu-sou. A subjectividade, enquanto feito desse cumprimento pelo próprio, não é, pois, uma fundamentação tranquila, mas um esforçar-se. Não é por acaso que as filosofias da subjectividade, ao seu nível mais alto, desembocam em teorias do trabalho.(...) Não surpreende, doravante, que a história do sujeito fosse, desde o início, uma história de attitudes - desde o estoicismo até ao existencialismo, desde os ardentes santos do deserto até aos jovens habitantes pacatos das grandes cidades —; sempre o sujeito se nos depara como um centro de esforços que se conserva a si próprio unido, como o princípio activo de uma atitude voltada contra o mundo exterior, inerte, informe e degradante, p. 129.

26 SLOTERDIJK, P. - Op. Cit., pp. 199-200.

27 DELEUZE, G. — Lógica do Sentido.... 267. 
da arte como a complexidade da existência humana e a relação desta com um espaço e um tempo determinados ${ }^{28}$.

Este programa artístico estende-se à multiplicação de discursos teóricos que, reflectindo sobre o sujeito e a identidade, potenciam a projecção do auto-retrato como espaço onde cada artista não promete estilos mas, antes, transforma o seu trabalho no espaço da (sua) experimentação, da radicalização artística; também não propõe qualquer determinação do Eu, qualquer ideal de Eu, qualquer promessa: (...) esta mentira onde se constrói o ideal, cheira-me a mentira e embus$t^{29}$. E mais adiante: Educar e disciplinar um animal que pode fazer promessas, não é tarefa paradoxal que se impôs com respeito o homem à Natureza? Não é este 0 verdadeiro problema da humanidade? ${ }^{30}$

Considerada durante quase meio século como cópia da realidade, a imagem fotográfica afirma-se agora como meio privilegiado através do qual se experienciam outros modos de subjectivação ou novas operações de despersonalização visíveis no recurso a estratégias visuais em obras cujos autores recorrem à apropriação, fragmentação, montagem, fotomontagem, justaposição, colagem, descontextualização, distanciando significado do significante ${ }^{31}$. Na superfície da imagem técnica se desfaz a imagem do sujeito.

Peter Sloterdijk citando uma conversa entre llya Kabakov e Boris Groys falanos desse caminho de ausência de plenitude. Nessa conversa diz Kabakov: Em mim é muito forte a disposição para não me sentir no meu lugar. Sempre foi para mim uma experiência especialmente agradável o não estar onde estivesse. Quando viajo, logo o gosto antecipado de partir daqui me faz feliz. Isto é, evidentemente, um trauma infantil pela falta de desejo de vir ao mundo. O mundo no qual nasci e a figura com a qual vim ao mundo deixam-me profundamente insatisfeito. Não gosto do meu aspecto e não me identifico com ele. Ainda me lembro que, quando vi pela primeira vez a minha imagem no espelho, gemi literalmente de dor: não podia conceber que eu era esse. Esse é o desejo de sair do meu corpo, das minhas coisas, da minha casa... Não me sinto em casa em lado nenhum, sinto-me sempre em estado de trânsito. De um homem assim costumava dizer-se: ele não está bem em nenhum lado ${ }^{32}$.

28 PICAZO, G. — «Estrategias de la representación: el sujeto, el objeto». La certeza vulnerable. Cuerpo y fotografía en el siglo XX (David Pérez ed.) Barcelona: Editorial Gustavo Gili, 2004, p. 251.

${ }_{29}$ NIETZSCHE, F. A genealogia da Moral. Lisboa: Guimarães Editores, 1976, p. 40.

30 NIETZSCHE, F. Op. Cit., p. 49.

31 (...) Podemos suspeitar que no âmbito da produção visual «de qualidade» — o antes chamado campo artístico —o género que por excelência permitirá em paralelo reconhecer «a eficácia produtora de sujectividade dos actos visuais» será consequente e logicamente, o auto-retrato(...)BREA, J.L. — «Fábricas de Identidad (retóricas del autorretrato)». Revista EXIT —Autorretratos. Madrid: no 10, 2003.

32 SLOTERDIJK, P. O Estranhamento do Mundo. Lisboa: Relógio D Água Editores, 2008, p. 73. 